\title{
Demencia por déficit de vitamina B12. Caso clínico
}

\author{
María Isabel Behrens $\mathrm{P}^{1,2}$, Violeta Díaz $\mathrm{T}^{1}$, \\ Carolina Vásquez $\mathbf{V}^{1 \mathrm{a}}$, Archibaldo Donoso $\mathbf{S}^{1}$. \\ Dementia caused by vitamin B12
deficiency. Report of one case
}

Cyanocobalamin (vitamin B12) deficiency can cause polyneuropathy, myelopathy, blindness, confusion, psychosis and dementia. Nonetheless, its deficiency as the sole cause of dementia is infrequent. We report a 59 years old man with a 6 months history of progressive loss of memory, disorientation, apathy, paranoid delusions, gait difficulties with falls, and urinary incontinence. He had suffered a similar episode 3 years before, with a complete remission. On examination there was frontal type dementia with Korsakoff syndrome, a decrease in propioception and ataxic gait. Cerebrospinal fluid examination showed a protein of $0.42 \mathrm{~g} / \mathrm{L}$ Brain computed tomography showed sequelae of a frontal left trauma. Brain single photon computed tomography (SPECT) was normal. Complete blood count showed a macrocytic anemia with a hematocrit $29 \%$ and a mean corpuscular volume of $117 \mu 3$. Plasma vitamin B12 levels were undetectable, erythrocyte folate levels were $3.9 \mathrm{ng} / \mathrm{ml}$ and plasma folate was normal. The myelogram showed megaloblastosis and the gastric biopsy showed atrophic gastritis. Treatment with parenteral B12 vitamin and folic acid reverted the symptoms, with normalization of the neuropsychological tests and reintegration to work (Rev Méd Chile 2003; 131: 915-9).

(Key Words: Dementia; Tomography, emiss on computed, single photon; Vitamin B12 deficiency).

Recibido el 1 de abril, 2003. Aceptado el 13 de junio, 2003.

${ }_{1}^{1}$ Departamento de Neurología y Neurocirugía, Hospital Clínico Universidad de Chile y ${ }^{2}$ Departamento de Neurología, Hospital Dr. Sótero del Río, Santiago de Chile. aPsicóloga

$\mathrm{L}$ a deficiencia de vitamina B12 (cianocobalamina) puede producir varios desórdenes neurológicos, incluyendo neuropatía periférica, degeneración subaguda combinada de la médula espinal, neuropatía óptica y alteraciones cogni-

Correspondencia a: Dr. Archibaldo Donoso S. Departamento de Neurología y Neurocirugía, Hospital Clínico Universidad de Chile. E mail: adonoso@entelchile.net tivas que van desde la confusión leve hasta la demencia o la psicosis ${ }^{1,2}$. La causa más frecuente de deficiencia de vitamina B12 es la anemia perniciosa, por baja producción de factor intrínseco asociado a atrofia gástrica y anaclorhidia, especialmente frecuente en personas de origen nórdico. Otras causas de malabsorción intestinal (resecciones intestinales, enfermedad de Crohn o dietas vegetarianas estrictas) también pueden llevar a un déficit de vitamina B12. Las alteraciones 
neurológicas secundarias a esta deficiencia pueden preceder a la anemia macrocítica ${ }^{2,3}$. Asimismo, en ciertos casos de anemia por déficit de vitamina B12 y ácido fólico, la anemia puede enmascararse por el tratamiento con este último ${ }^{4}$.

La deficiencia de vitamina B12 es una causa muy poco frecuente de demencia reversible, especialmente como causa única ${ }^{3}$. Consiste en una disfunción cognitiva global con lentitud, falta de concentración y fallas de la memoria. Son frecuentes las manifestaciones psiquiátricas: depresión, manía y psicosis paranoídea con alucinaciones visuales y auditivas. No se describen afasia ni otros defectos neurológicos focales.

Se presenta un paciente con un deterioro cognitivo progresivo de 6 meses de evolución asociado a déficit de vitamina B12, que revirtió completamente con el tratamiento con esa vitamina.

\section{Caso Cúnico}

Hombre de 59 años de edad, casado, contador, que presentaba un cuadro de inicio insidioso con fallas de memoria, apatía y depresión. Progresivamente se agregaron conductas inadecuadas, ideas delirantes de persecución y desorientación espacial, por lo cual debió dejar el trabajo. Las últimas semanas se agregaron incontinencia urinaria y alteración de la marcha con caídas frecuentes, motivo por lo cual fue hospitalizado. Entre sus antecedentes destacaba un episodio similar cuatro años antes, del que se recuperó completamente, sin que se sepa de un tratamiento específico, aunque es probable que haya recibido inyecciones de vitamina $B$, dado el uso frecuente de este tratamiento en nuestra población. En la niñez había sufrido un traumatismo encéfalo craneano frontal izquierdo, operado sin secuelas.

El examen mental de ingreso mostró notoria bradipsiquia, con apatía y actitud suspicaz. Había desorientación témporo-espacial, conductas de imitación y perseveración. Fallaba en memoria, con confabulaciones y falsos reconocimientos. Presentaba algunos elementos del síndrome de
Gerstmond como desorientación derecha-izquierda, acalculia y aguosa digital visual. Su lenguaje era lacónico, sin afasia ni disartria. El examen neurológico mostró paratonía y ataxia de la marcha que impedía la deambulación. Presentaba reflejos osteotendíneos vivos, plantares flexores, disminución de la sensibilidad profunda y un esbozo de reflejos arcaicos.

El estudio neuropsicológico mostró: Minimental test de Folstein*: 16/30 (Tabla); prueba de Matrices Progresivas Coloreadas de Raven ${ }^{* *}$ : 9/36. En el aprendizaje de palabras ${ }^{* * *}$ su rendimiento fue 29/100 palabras, con un reconocimiento de 9/ 10. En memoria semántica (o categorial) ${ }^{*+* k *}: 5$ elementos (rango inferior).

Laboratorio. Hemograma: anemia macrocítica, con hematocrito $29 \%$, volumen corpuscular medio de $117 \mu 3$ y neutrófilos polisegmentados. El nivel de vitamina B12 fue $0 \mathrm{pg} / \mathrm{ml}$ (normal $>179 \mathrm{pg}$ ), ácido fólico plasmático: $15 \mathrm{ng} / \mathrm{ml}$ (normal $>2,8)$ y ácido fólico eritrocítico: 3,88 ng/ml (normal >148,8). El mielograma mostró hipercelularidad de las 3 series con marcados cambios megaloblásticos. Los otros exámenes sanguíneos (electrolitos, perfil bioquímico, hepático, lipídico y creatinina) no mostraban alteraciones. El líquido céfalo-raquídeo resultó transparente, agua de roca, con citoquímico normal excepto un leve aumento de las proteínas $(0,42 \mathrm{~g} / \mathrm{L})$. El cultivo y la búsqueda de células neoplásicas fueron negativos. La tomografía computada cerebral (TAC) reveló elementos involutivos mayores que lo esperado para la edad y una lesión hipodensa frontal izquierda de aspecto secuelar. El SPECT fue normal. Para el estudio de la anemia megaloblástica se realizaron una endoscopia digestiva y biopsia gástrica que reveló un pólipo gástrico y una metaplasia intestinal. Se plantearon como posibles diagnósticos: demencia por déficit de vitamina B12, demencia frontotemporal y como menos probable una demencia tipo Alzheimer.

Durante la hospitalización presentó agitación nocturna con alucinaciones visuales y auditivas que requirieron de tranquilizantes mayores. Llamó la atención que durante su evaluación neuropsicológica

\footnotetext{
"Minimental de Folstein: Instrumento de tamizaje de deterioro cognitivo que incluye pruebas de orientación, memoria, concentración, lectoescritura y dibujo. Puntaje óptimo: 30. ${ }^{* *}$ Matrices Progresivas Coloreadas: Prueba de capacidad intelectual visuoespacial que obliga a conceptualizar relaciones espaciales de diseño. Puntaje óptimo: 36. *** Aprendizaje de palabras: Prueba de memoria episódica que implica aprender una serie de 10 palabras repetidas durante 10 ensayos. Puntaje máximo teórico: 100. ${ }^{* w 1 \times}$ Memoria semántica o fluidez verbal, mide ítemes de una categoría (ej: animales) durante 60 s. Mínimo aceptable: 23.
} 
presentaba fluctuaciones de los rendimientos, lo cual hizo pensar en una pseudodemencia. Estas observaciones fueron concordantes con la impresión de un psiquiatra, que las interpretó como un estado confusional. Se inició tratamiento con vitamina B12 (5000 U im diaria durante 10 días y luego semanal), además de $3 \mathrm{mg}$ de ácido fólico al día por vía oral. La Tabla muestra la evolución del Minimental test durante y después de su hospitalización. Se observó una mejonía en todos los ítemes de la prueba, pero con fluctuaciones importantes en la atención y cálculo de un día para otro. La Tabla también muestra la evolución favorable del hemograma en relación con el inicio del tratamiento con vitamina B12.

El paciente recuperó paulatinamente la orientación y la memoria. En su primer control, un mes después del alta, el Minimental test era de 30/30 (Tabla). Presentaba mínima dificultad en la marcha y

\section{Tabla 1. Evolución del M inimental test de Folstein y de algunos parámetros del hemograma durante la hospitalización y después del inicio del tratamiento con vitamina B12 (14-6-2002)}

\begin{tabular}{|lllllll|}
\hline Fecha (día-mes) 2002 & $10-6$ & $12-6$ & $16-6$ & $17-6$ & $19-6$ & $18-8$ \\
Minimental test de Folstein & 16 & 19 & 17 & 22 & 24 & 30 \\
Eritrocitos (millones x mm3) & 2,6 & 3,2 & & 3,14 & & 4,6 \\
Hematocrito (\%) & 29 & 36 & & 35 & & 43 \\
Volumen corpuscular medio & 113,6 & 118 & & 112 & & 94 \\
\hline
\end{tabular}
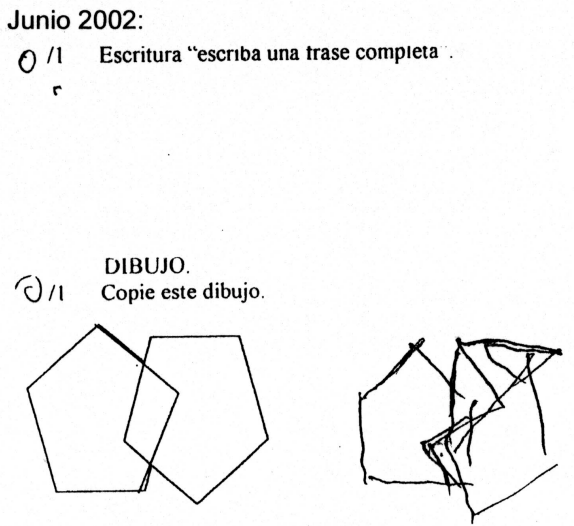

Agosto 2002

11 Escritura "escriba una trase completa"

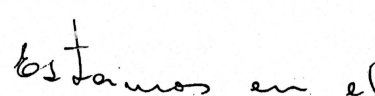
el Yoospital de le Diвuso. $U$ de phile.
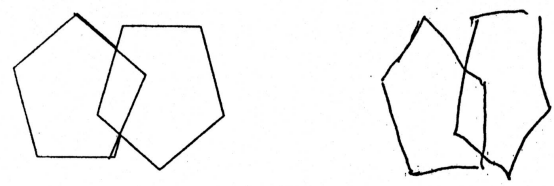

Figura 1. Reproducción de la escritura y copia de los pentágonos del Minimental antes y después del tratamiento con vitamina B12. 
parestesias distales. Dos meses después del inicio del tratamiento, en una nueva evaluación neuropsicológica obtuvo 30/36 puntos en Matrices Progresivas Coloreadas; en aprendizaje de palabras (Barcelona) llegó a 86/100 palabras, con 9/10 en evocación a los 10 min y 10/10 en reconocimiento. En memoria semántica (animales) evocó 18 palabras en 60 segundos (percentil 60, rango medio superior); en evocación de palabras con $\mathrm{P}$ logró 25 en 3 min (percentil 60, rango medio superior). En la prueba de Stroop (función frontal) no hubo interferencia. El hemograma se había normalizado. Una segunda biopsia gástrica mostró gastritis atrófica.

El paciente se reintegró al trabajo.

\section{DisCUSIÓN}

Este paciente representa uno de los pocos cuadros de demencia realmente reversible, ya que incluso en entidades tales como el hidrocéfalo normotensivo y el hematoma subdural crónico la mejoría del deterioro cognitivo después de la intervención, muchas veces es sólo parcial. Su recuperación ad integrum permite descartar las demencias degenerativas, como una demencia frontotemporal, que se sospechó por las precoces alteraciones conductuales. La evolución también permitió descartar una enfermedad de Creutzfeld-Jacob y el estudio del LCR descartó otras causas de demencias subagudas, como una meningitis crónica o una infiltración carcinomatosa meníngea. La deficiencia de vitamina B12 puede causar leve aumento de la proteína del líquido céfalo-raquídeo ${ }^{1}$.

La buena respuesta del cuadro neurológico al tratamiento con vitamina B12, que coincidió con la mejoría del hemograma, nos permite concluir que la demencia fue causada por la deficiencia de cianocobalamina. Una nueva biopsia gástrica confirmó el diagnóstico de anemia perniciosa y el antecedente de un episodio similar cuatro años antes es concordante con el diagnóstico.

La cianocobalamina participa en una serie de reacciones bioquímicas que involucran la metilación de diversos metabolitos. El daño neurológico que ocure en su deficiencia puede ser consecuencia de las alteraciones vasculares asociadas a la elevación de la homocisteína ${ }^{5,6}$, a alteraciones en la metilmalonil CoA mutasa 7 , o a defectos en las reacciones de metilación ${ }^{8-10}$. Estos últimos alteran la proteína básica de la mielina, lo que impide su comecta conformación 0 acelera su destrucción ${ }^{11,12}$. Tanto el daño vascular de pequeño vaso como las fallas de mielinización (especialmente de sustancia blanca subcortical) pueden explicar las alteraciones cognitivas. Desde el punto de vista neuropsicológico, la pregnancia de los trastornos conductuales, la apatía, bradipsiquia, las alteraciones de la marcha, incluso las fluctuaciones de los rendimientos, permiten catalogar este caso como una demencia fronto-subcortical ${ }^{13}$.

La importancia de la deficiencia de cianocobalamina como causante de demencia es discutida. Lindenbaum et al, en $1988^{3}$, mostraron que ancianos con deficiencia de B12 tenían deterioro cognitivo en ausencia de manifestaciones hematológicas y que en muchos casos, aunque no todos, los trastomos cognitivos revertían al corregir los niveles de vitamina. Estudios posteriores apoyan estos resultados ${ }^{14-}$ 16. En pacientes con enfermedad de Alzheimer comprobada histológicamente, se han descrito también niveles séricos más bajos de vitamina $B 12^{17} \mathrm{y}$ una asociación entre las alteraciones conductuales y los niveles de vitamina ${ }^{18}$. Por otra parte, en el estudio habitual de pacientes con probable enfermedad de Alzheimer es frecuente encontrar niveles subnormales de vitamina B12, sin que su administración modifique el cuadro clínico en forma evidente. Es posible que ello se deba a que son observaciones clínicas aisladas, 0 a que la carencia nunca fue tan severa como en nuestro caso (el nivel plasmático era $0 \mathrm{pg} / \mathrm{ml}$ ), o que la carencia ya hubiera producido daño irreversible. Esto último parece poco probable si se considera la facilidad con la cual revirtió una demencia tan grave como la de nuestro paciente. Además, podemos recordar que en los vegetarianos es frecuente encontrar niveles subnormales de $\mathrm{B} 12^{19}$, que no necesariamente tienen efectos sobre el sistema nervioso.

Nuestra conclusión es que la demencia por carencia de B12 es excepcional, éste es el primer caso en la experiencia de los autores, pero existe. Como una curiosa coincidencia, hace pocos meses se publicó en la Folia Psiquiátrica el caso de un paciente joven con estado confusional subagudo por carencia de cianocobalamina ${ }^{20}$. Nosotros catalogamos a nuestro paciente de demencia por la conservación de la vigilia y por la duración del cuadro, pero debemos reconocer que existían fluctuaciones de sus rendimientos, lo que lo aproximaba a un cuadro de compromiso de conciencia. 


\section{REFERENCIAS}

1. Aminoff MJ, Greenberg DA, Simon RP. Disorders of Cognitive Functions: Approach to diagnosis and acute confusional states. En: Aminoff MJ, Greenberg DA, Simon RP, eds. Clinical Neurology. USA: Appleton and Lange, $3^{\text {er }}$ edition, 1996; 20.

2. Kunze K, Leitenmaier K. Vitamin B12 deficiency and subacute combined degeneration of the spinal cord. En: PJ Vinken y GW Bruyn eds: Handbook of Clinical Neurology. Amsterdam: North Holland Publ Co, 1976; 28: 141-98.

3. Lindenbaum J, Healton EB, Savage DG, Brust JC M, Garrett TJ, Podell ER et al. Neuropsychiatric disorders caused by cobalamin deficiency in the absence of anemia or macrocytosis. N Engl J Med 1988; 318: 1720-8.

4. Hirsch S, de la Maza P, Barrera G, Gattas V, Petermann M, Bunout D. The Chilean flour folic acid fortification program reduces serum homocysteine levels and masks vitamin B-12 deficiency in elderly people. J Nutr 2002; 132: 289-91.

5. Clarke R, Daly L, Robinson $K$, Naughten E, Cahalane S, Fowler B et al. Hyperhomocysteinemia: an independent risk factor for vascular disease. N Engl J Med 1991; 324: 1149-55.

6. Fasbender K, Mielke O, Bertsch T, NAFe B, Froschen $\mathrm{S}$, HennerRici M. Homocysteine in cerebral macroangiopathy and microangiopathy. Lancet 1999; 353: 1856-7.

7. METZ J. Cobalamin deficiency and the pathogenesis of nervous system disease. Ann Rev Nutr 1992; 12: 59-79.

8. Bottigleri T. Folate, vitamin B12 and neuropsychiatric disorders. Nut Rev 1996; 54: 382-90.

9. Aulen RH, Stabier SP, Savage DG, Lindenbaum J. Metabolic abnormalities in cobalamin (vitamin B12) and folate deficiency. Faseb J 1993; 7: 1344-53.
10. Chiang PK, Gordon RK, Tal J, Zeng GC, Doctor BP, Paradhasaradhi K, McCann PP. S-adenosylmethionine and methylation. Faseb J 1996; 10: 471-80.

11. Weir DG, Sсотт JM. Brain function in the elderly: role of vitamin B12 and folate. Br Med Bull 1999; 55: 669-82.

12. Bucceliato FR, Miloso M, Braga M, Nicolini G, Morabito A, Pravettoni G et al. Myelinolytic lesions in spinal cord of cobalamin deficient rats are TNF $\alpha$ mediated. Faseb J 1999; 13: 297-304.

13. Joynt RJ, Shoulson I. Dementia. En: Clinical neuropsychology, KM Heilman y E Valenstein eds. 2th. Ed Oxford University Press, New York 1985.

14. Riggs KM, Spiro A, Tucker K, Rusch D. Relations of vitamin B-12, vitamin B-6 and homocysteine to cognitive performance in the Normative Aging Study. Am J Clin Nutr 1996; 63: 306-14.

15. McCaddon A, Davies G, Hudson P, Tandy S, Cattell $\mathrm{H}$. Total serum homocysteine in senile dementia of Alzheimer type. Int J Geriatr Psychiatry 1998; 13: 235-9.

16. Johnson MA, Hawthorne NA, Brackett WR, Fischer JG, Gunter EW, Aluen RH et al. Hyperhomocysteinemia and vitamin B-12 deficiency in elderly using Title IIIc nutrition services. Am J Clin Nutr 2003; 77: 211-20.

17. Ciarke R, Smith D, Jobst KA, Refsum $H$, Sutton L, UEIAND PM. Folate, vitamin B12 and serum total homocysteine levels in confirmed Alzheimer disease. Arch Neurol 1998; 55: 1440-55.

18. Meins W, Mulier-Thomsen T, Meier-Baumgartner HP. Subnormal serum vitamin B12 and behavioural and psychological symptoms in Alzheimer's disease. Int J Geriatr Psychiatry 2000; 15: 415-8.

19. AleXANDer D, BaLl MJ, ManN J. Nutrient intake and haematological status of vegeterians and age sex matched omnivors. 1994; 48: 538-46.

20. Vera G, Quezada T. Debut psiquiátrico de déficit de vitamina B12. Folia Psiquiátrica 2002; 7: 47-52. 